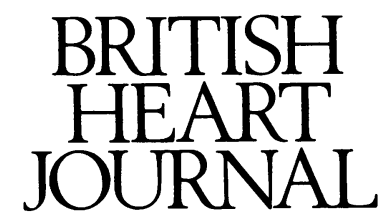

\title{
Editorial
}

\section{Electrical neurostimulators for pain relief in angina}

The idea that stimulating afferent nerve fibres can relieve pain grew out of Melzack and Wall's gate theory of pain. ${ }^{1}$ According to this concept, stimulation of large afferent $A$ fibres (which do not transmit pain) reduces the input to the brain from the peripheral pain receptors via the small myelinated and unmyelinated $\mathrm{C}$ fibres. The theory gives a crude explanation for the variability of the sensation of pain. High frequency stimulation with pulse widths of between 100 and $200 \mu \mathrm{s}$, which stimulates the large A fibres (but not the $C$ fibres), reduced the sensation of pain. ${ }^{2}$ This technique was used with some success to treat chronic pain, initially with external transcutaneous stimulators and more recently with direct spinal cord stimulation via epidural electrodes. ${ }^{3}$ In a few patients intermittent claudication was also relieved and indeed many had noted a sensation of warmth in their legs when neurostimulation was applied. ${ }^{45}$ Further work has confirmed that neurostimulation is useful in severe peripheral vascular disease in relieving pain, healing trophic ulcers, and increasing capillary blood flow and transcutaneous oxygen tension..$^{5-8}$ The effects are similar to those of sympathectomy.

Indeed sympathectomy was used to treat angina, and Apthorp et al in 1964 found that it relieved angina in about $75^{\circ}$ of patients. ${ }^{9}$ The use of neurostimulation to relieve angina follows logically from its use in peripheral vascular disease. Its development was cramped, however, by the fact that if pain is inhibited ischaemia will continue unabated. But it is now clear that the relation between angina and ischaemia, as illustrated by the increasing awareness of silent ischaemia, is not constant and painful stimuli may be modified by many factors. ${ }^{10-13}$ It is increasingly apparent that neurostimulation is not dangerous and it can help patients who have severe intractable angina despite standard treatment. ${ }^{14-22}$

\section{Techniques and mode of stimulation}

In transcutaneous nerve stimulation two large silicon rubber electrodes (connected to a battery powered neurostimulator) are placed over the area of pain and on the other side of the spine in the same dermatome to produce segmental stimulation. Pulse widths of $100-200 \mu$ s (and frequency between 75 and $150 \mathrm{~Hz}$ ) selectively stimulate the large fibres and produce a tingling sensation or parasthesia.

However, transcutaneous nerve stimulation limits the patient's mobility and sensitivity or rashes occur around the electrodes. Therefore, implantable systems have been developed. The epidural electrode (unipolar or bipolar) is inserted through a standard epidural puncture, which is positioned to produce parasthesia in the area of the pain, and is connected to a neurostimulator unit that is implanted in an axillary pouch.

\section{Mechanism of action}

The connection between ischaemia and pain is complex and it is not known how neurostimulation influences this. There are several possibilities.

Does neurostimulation increase coronary blood flow? Non-invasive studies suggested that there was less ischaemia in some patients. ${ }^{14-1720-22}$ A recent study from Belgium assessed regional myocardial perfusion by positron emission tomography with potassium-38 as a tracer in seven patients with epidural spinal cord stimulators before and after exercise. ${ }^{23}$ There was no significant increase of perfusion to abnormal segments after maximal exercise despite a reduction in angina and an increased time to the onset of ischaemia, although perfusion during stimulation at rest was higher than in the controls. In peripheral vascular disease, however, epidural neurostimulation improved microvascular blood flow. ${ }^{78} \mathrm{It}$ is likely that any changes in perfusion are small, occur mainly in the ischaemic areas, and will be difficult to detect in the heart. Local flow can be adjusted without any increase in total flow, for example the so-called "Robin Hood" effect of aminophylline. ${ }^{24}$

The effects of neurostimulation have been likened to sympathectomy. Although the relief of pain alone may indirectly reduce ischaemia by reducing reflex sympathetic nervous activity, stimulation of the dorsal column may have a direct effect. Currents spread from the dorsal columns into the intermediate-columns of the grey area, releasing segmental spinal reflexes that tonically inhibit sympathetic discharge and this may cause vasodilatation. Prostaglandins may be involved too. Hilton and Marshall showed vasodilatation in the cat gastrocnemius muscle after dorsal root stimulation. ${ }^{25}$ It was unaffected by sympathetic blocking agents and greatly reduced by prostaglandin inhibitors. They concluded that activity in the afferent fibres of skeletal muscle produces an increase in muscle blood flow mediated by the release of prostaglandins. The same mechanism may be active in the heart.

Direct suppression or inhibition of pain pathways in the spinal cord is one of the most likely mechanisms. Recent experimental work has shown that dorsal column stimulation inhibits activity of spinothalamic tract cells evoked by the electrical stimulation of cardiopulmonary sympathectic afferents and by intracardiac bradykinin. ${ }^{26}$ Thus it is likely that dorsal column stimulation directly inhibits the transmission of nocioceptive cardiac stimuli and thus lessens the sensation of pain. 
Another mechanism for pain suppression is stimulation of endogenous opiates. Low frequency electroacupuncture has been shown to cause a rise in concentrations of $\beta$ endorphin (but not met-enkephalin) in the cerebrospinal fluid in association with relief of pain. ${ }^{27}$ Naloxone can reverse the effect of acupuncture. ${ }^{28}$ In patients with exercise induced myocardial ischaemia, plasma concentrations of endorphin are increased with exercise, and concentrations after exercise are related to the time to onset of angina and it is possible that endorphins may alter the perception of pain caused by myocardial ischaemia. ${ }^{29}$ It has been suggested that transcutaneous nerve stimulation and epidural spinal electrical stimulation can increase concentrations of $\beta$ endorphin. However, Mannheimer and his colleagues showed that naloxone, which is a pure opiate antagonist, does not abolish the effect of transcutaneous nerve stimulation. ${ }^{17}$ Electroacupuncture, however, usually uses low frequency stimulation which increases $\beta$ endorphins which can be antagonised by naloxone, whereas the high frequency stimulation used with transcutaneous nerve stimulation may release met-enkephalins which are not blocked entirely by conventional doses of naloxone. Opiate peptides may be involved in modulating sympathetic activity within the heart (which has opiate receptors) especially during stress, pain, or hypoxia. ${ }^{28-30}$ Until more specific agonists and antagonists are available to probe the action of opioid peptides, any possible action of neurostimulation via endorphins remains mere speculation.

\section{Clinical results in patients with angina}

The clinical use of epidural neurostimulation for patients with angina is limited. Assessment of these techniques is difficult because the treatment of painful conditions is especially susceptible to the placebo effect. But sham studies or double blind placebo controlled trials are impossible with neurostimulators because the patient feels parasthesia and the electrical activity interferes with electrocardiographic recordings. The use of transcutaneous nerve stimulation in the treatment of angina patients has been studied in depth by Mannheimer and his colleagues. ${ }^{14-17}$ They showed that treatment with transcutaneous nerve stimulation reduces pain, increases tolerance to pacing, improves lactate metabolism, and is associated with less pronounced ST segment depression. In long term studies the group treated with transcutaneous nerve stimulation had increased work capacity (as assessed by repeated bicycle ergometry tests), reduced frequency of angina attacks, and reduced consumption of nitrates compared with an untreated control group. We found that transcutaneous nerve stimulation was useful for the control of severe angina and rest pain in patients who were not candidates for operation. The effect was often impressive.

The first report of epidural neurostimulation for the relief of angina was that of Murphy and Giles from Perth, Australia. ${ }^{18}$ They described relief of angina after implantation in a 54 year old woman with a long history of angina. In a later report Murphy and Giles described another 10 patients who had good clinical benefit. ${ }^{19}$ Mannheimer and his colleagues reported on a further 10 patients, ${ }^{20}$ confirming the considerable clinical improvement that was associated with an increase of working capacity and time to angina, less ST segment depression, and a shortened recovery time. Our results in 11 patients were promising. ${ }^{21} 22$ We did not abolish angina in all patients but in some the improvement was remarkable, with a significant drop in consumption of glyceryl trinitrate. Some have returned to work. Treadmill exercise testing showed an increase in exercise duration and some lessening of ST segment depression at comparable work loads. None the less, there does not seem to be any close relation between symptomatic improvement and reduction of ischaemia on exercise testing or right atrial pacing and there seems to be a mixture of pain relief and reduction of ischaemia. The beneficial effects have persisted for more than a year and to date we have no evidence that mortality is increased; however, the numbers treated remain small. The prolonged improvement argues against any placebo effect, especially in these patients who often had a rapid recurrence of pain after coronary artery bypass grafting.

It seems that both transcutaneous nerve stimulation and epidural spinal electrical stimulation are useful techniques for the relief of angina. Pain may be inhibited both centrally in the spinal cord and peripherally in the heart and the relief of pain may lessen ischaemia by a reduction of sympathetic nervous activity. The effect of neurostimulation is sometimes so considerable that factors other than mere pain relief must be involved, such as a redistribution of local blood flow to ischaemic areas as occurs in patients with peripheral vascular disease. Neurostimulation is not therefore an eccentric offshoot of acupuncture but is likely to become a useful treatment. Furthermore, discovering how it works may clarify the complex mechanisms of ischaemic pain.

J E SANDERSON

Department of Cardiology,

Taunton and Somerset Hospital,

Musgrave Park,

Taunton, Somerset TA1 5DA

Melzack R, Wall PD. Pain mechanisms: a new theory. Science $1965 ; 150$ 971-9.

Wall PD, Sweet WH. Temporary abolition of pain in man. Science 1967;155:108-9.

Shealy CN, Mortimer JT, Hagfors NR. Dorsal column electroanalgesia. Neurosurg 1970;32:560-4.

4 Friedman H, Nashold BS, Somjen G. Physiological effects of dorsal column stimulation. Adv Neurol 1974;4:769-71.

5 Tallis RC, Illis LS, Sedgewick EM, Hardwidge C, Garfield JS. Spinal cord stimulation in peripheral vascular disease. J Neurol Neurosurg Psychiatry 1983;46:478-84.

6 Augustinsson LE, Holm J, Carlsson C-A, Jivegard L. Epidural electrical stimulation in severe limb ischaemia. Evidences of pain relief, increased blood flow and a possible limb saving effect. Ann Surg 1985;202:104-11.

7 Jacobs M, Jorning PJG, Joshi SR, Kitslaar P, Slaaf DW, Reneman RS Epidural spinal cord electrical stimulation improves microvascular blood flow in severe limb ischaemia. Ann Surg 1988;207:65-9.

8 Sciacca V, Tamorri $\mathrm{M}$, Rocco $\mathrm{M}$, et al. Modification of transcutaneous oxygen tension in lower limb peripheral arterial occlusive disease patients treated with spinal cord stimulation. Ital J Surg Sci 1986;16:279-82.

9 Apthorp GH, Chamberlain DA, Hayward GW. The effects of sympathectomy on the electrocardiogram and effort tolerance in angina pectoris. $B$ Heart $J$ 1964;26:218-26.

0 Deanfield JE, Selwyn AP, Chierchia S. Myocardial ischaemia during daily life in patients with stable angina; its relation to symptoms and heart rate changes. Lancet 1983;ii:753-8.

11 Maseri A, Chierchia S, Davies G, Glazier J. Mechanisms of ischemic cardiac pain and silent myocardial ischemia. Am J Med 1985;79(suppl 3A):7-11.

12 Levy RD, Shapiro LM, Wright C, Mockus LJ, Fox KM. The haemodynamic significance of asymptomatic ST segment depression assessed by ambulatory pulmonary artery pressure monitoring. $\mathrm{Br}$ Heart 1986;56:526-30.

13 Sylvern C. Angina pectoris. Clinical character, neurophysiological and molecular mechanisms. Pain 1989;36:145-67.

14 Mannheimer C, Carlsson C-A, Vedin A, Wilhelmsson C. Transcutaneous electrical nerve stimulation (TENS) in angina pectoris. Pain 1986;26: 291-300.

15 Emanuelsson A, Mannheimer C, Waagstein F, Wilhelmsson C. Catecholamine metabolism during pacing induced angina pectoris and the effect of transcutaneous electrical nerve stimulation. Am Heart $J$ 1987;114:1360-6.

16 Mannheimer C, Carlsson C-A, Emanuelsson H, Vedin A, Waagstein F, Wilhelmsson $C$. The effects of transcutaneous electrical nerve stimulation in patients with severe angina pectoris. Circulation 1985;71:308-16.

17 Mannheimer C, Emanuelsson H, Waagstein F, Wilhelmsson C. Influence of naloxone on the effects of high frequency transcutaneous electrical nerve stimulation in angina pectoris induced by atrial pacing. Br Heart 1989;62:36-42.

18 Murphy DF, Giles KE. Intractable angina pectoris: management with dorsal column stimulation (case report). Med $J$ Aust 1987;146:260

19 Murphy DF, Giles KE. Dorsal column stimulation for pain relief from intractable angina pectoris. Pain 1987;28:365-8.

20 Mannheimer C, Augustinsson L-E, Carlsson C-A, Manhem K, Wilhelmsson $C$. Epidural spinal electrical stimulation in severe angina pectoris. $B$ Heart $J$ 1988;59:56-61. 
21 Sanderson JE, Waterhouse TD, Neubauer K, Palmer R. Epidural spinal timulation in patients suffering from intractable angina [Abstract]. $\mathrm{J} \mathrm{Am}$ Coll Cardiol 1989;13:46A.

22 Sanderson JE, Waterhouse TD, Palmer RBG. Epidural spinal stimulation in patients with intractable angina [Abstract]. Br Heart J 1989;61:462.

23 Landsheere C, Habets A, Mannheimer C, et al. Epidural stimulation in angina pectoris: any effect on regional myocardial perfusion? [Abstract]. Circulation 1988;78(suppl II):32.

24 Crea F, Pupita G, Galassi AR, et al. Effect of theophylline on exercise induced myocardial ischaemia. Lancet 1989;i:683-6.

25 Hilton SM, Marshall JM. Dorsal root vasodilatation in cat skeletal muscle. J Physiol (Lond) 1980;299:277-88.

26 Foreman RD, Chandler MJ, Brennan K, Kim S, Garrison DW, Schwartz
PJ. Does dorsal column stimulation reduce the activity of spinothalamic tract cells that respond to cardiac input [Abstract]. Circulation 1989;80(suppl II):552.

27 Clement-Jones V, McLoughlin L, Tomlin S, Besser GM, Rees LH, Wen HL. Increased beta-endorphin but not met-enkephalin levels in human cerebrospinal fluid after acupuncture for recurrent pain. Lancet 1980;ii:946-8.

28 Thompson JW. Opioid peptides. Br Med J 1984;288:259-60.

29 Sheps DS, Adams KF, Hinderliter A, et al. Endorphins are related to pain perception in coronary artery disease. Am J Cardiol 1987;59:523-7.

30 Ledda F, Mantelli L, Corti V. Sensitivity to dynorphin-(1-13) of the presynaptic inhibitory opiate receptors of the guinea-pig heart. Eur Pharmacol 1985;117:377-80.

\section{Cardiac defects in the children of mothers with high concentrations of plasma phenylalanine}

Postnatal brain damage in a homozygous affected child with phenylketonuria is well recognised. Less well known, despite its recognition over thirty years ago $^{1}$, is the damage that even a heterozygous fetus can incur in a homozygous mother with high blood concentrations of phenylalanine. Low birth weight, microcephaly, mental retardation, and congenital heart disease are most often seen but other defects of structure have been reported. Lenke and Levy in their retrospective survey found congenital heart disease in $12-15 \%$ of the offspring of untreated mothers with classic phenylketonuria. ${ }^{2}$ Typically these women had phenylalanine concentrations in excess of $1200 \mu \mathrm{mol} / 1$, more than 15 times the normal value. Because the placenta transports amino acids actively, fetal blood concentrations are higher than those in the mother-with the ratio of fetus to mother for phenylalanine being around $1 \cdot 6$. There is evidence too that high maternal phenylalanine values may decrease the transfer of some other amino acids across the placenta ${ }^{3}$ so that the fetus may have immensely high concentrations of phenylalanine but be relatively deficient in some other amino acids. Similarly, in animals there is evidence that high fetal blood concentrations of phenylalanine may interfere with the transport of other amino acids through the blood brain barrier into the central nervous system. ${ }^{4}$ Poor fetal growth, low birth weight, microcephaly, and mental retardation may all be ascribed to the resulting amino acid imbalances quite apart from other possible toxic effects of phenylalanine or its metabolites.

The sensitivity of the postnatal brain to high concentrations of phenylalanine has been known for decades. Congenital heart disease, however, is different. The congenital cardiac abnormalities are classic defects of organogenesis that can be traced back to the fifth to eighth weeks of fetal life during which the heart develops from a simple tube into a four chambered structure with separate atrioventricular canals and separate outflow tracts developing from the common truncus arteriosus. The congenital defects in maternal phenylketonuria have included coarctation of the aorta, hypoplastic left ventricle, mitral valve atresia, ventricular septal defects, Fallot's tetralogy, ${ }^{5}$ and now, as reported on page 180 of this issue, an anomalous coronary artery. ${ }^{6}$ There are some major unanswered questions. For example, is any particular pattern of congenital cardiac defects commoner in maternal phenylketonuria? Why should the heart apparently be the next most vulnerable organ in the fetus after the central nervous system? The incidence of mental retardation in untreated maternal phenylketonuria when the mother's phenylalanine exceeds $1200 \mu \mathrm{mol} / 1$ is around $90 \%$ and the incidence of microcephaly only slightly less. These incidences are much higher than that of congenital heart disease but the question of unexpected cardiac susceptibility remains.

One theory relates to a link between the developing central nervous system and the embryonic heart. Kirby and Miyagawa have drawn attention to the evidence that neural crest cells are important for normal cardiac development. ${ }^{7}$ The neural crest cells migrate away from the neural plate as it closes to form the neural tube. Incidentally, a higher incidence of neural tube abnormalities has not yet been reported in the offspring of mothers with phenylketonuria. Cranial neural crest cells move during normal embryonic development into the pharyngeal arches and pharyngeal region. Some of these, the cardiac neural crest cells, have been identified in association with the aortic arch arteries and the developing outflow tract. Studies of neural crest ablation in developing chick embryos produced various cardiac anomalies and it seems that migrating neural crest cells are critical in the control of cardiac development. Could congenital cardiac damage in maternal phenylketonuria ultimately be the result of another adverse effect on cells of neural plate origin-in addition to the adverse effects on the same tissue that lead to microcephaly and mental retardation? Unifying hypotheses are always attractive. Proof is more difficult. Other defects of organogenesis-such as oesophageal atresia-have been described in the offspring of mothers with phenylketonuria ${ }^{2}$ but whether these can be linked to an adverse effect on neural crest cells has not been suggested and indeed it is not clear whether these defects are truly more common than in the normal population. Proof that maternal phenylalanine in some way adversely affects the fetal heart through an effect on neural crest cells will need experimental work in animals that closely models the human biochemical defect. Work on that has started. 